\title{
A siderophore biosynthesis gene cluster from the fish pathogen Photobacterium damselae subsp. piscicida is structurally and functionally related to the Yersinia high-pathogenicity island
}

\author{
Carlos R. Osorio, Sandra Juiz-Río and Manuel L. Lemos
}

Correspondence

Manuel L. Lemos

mlemos@usc.es

Received 7 June 2006

Revised 26 July 2006

Accepted 3 August 2006
Department of Microbiology and Parasitology, Institute of Aquaculture and Faculty of Biology, University of Santiago de Compostela, Santiago de Compostela 15782, Galicia, Spain

\begin{abstract}
Photobacterium damselae subsp. piscicida, the causative agent of fish pasteurellosis, produces a siderophore which is distinct from that produced by $P$. damselae subsp. damselae. Using suppression subtractive hybridization, a subsp. piscicida-specific DNA region of $35 \mathrm{~kb}$ was identified in strain DI21, and 11 genes were defined: $d a h P, \operatorname{araC1}, \operatorname{araC2}, \operatorname{frpA}$, irp8, irp2, irp1, irp3, irp4, irp9 and irp5. The sequence of the predicted proteins encoded by these genes showed significant similarity with the proteins responsible for the synthesis and transport of the siderophore yersiniabactin, encoded within the Yersinia high-pathogenicity island (HPI). Southern hybridization demonstrated that this gene cluster is exclusive to some European subsp. piscicida isolates. Database searches revealed that a similar gene cluster is present in Photobacterium profundum SS9 and Vibrio cholerae RC385. An irp1 gene (encoding a putative non-ribosomal peptide synthetase) insertional mutant (CS31) was impaired for growth under iron-limiting conditions and unable to produce siderophores, and showed an approximately 100-fold decrease in degree of virulence for fish. The subsp. piscicida DI21 strain, but not CS31, promoted the growth of a Yersinia enterocolitica irp1 mutant. Furthermore, a yersiniabactin-producing $Y$. enterocolitica strain as well as purified yersiniabactin were able to cross-feed strains DI21 and CS31, suggesting that the subsp. piscicida siderophore might be functionally and structurally related to yersiniabactin. The differential occurrence among $P$. damselae strains, and the low sequence similarity to siderophore synthesis genes described in other members of the Vibrionaceae, suggest that this genetic system might have been acquired by horizontal transfer in $P$. damselae subsp. piscicida, and might have a common evolutionary origin with the Yersinia HPI.
\end{abstract}

\section{INTRODUCTION}

Iron is an essential element for most bacteria; however, most of the iron in biological systems is chelated by high-affinity iron-binding proteins. Therefore, pathogens have developed efficient mechanisms to obtain iron from the host and to establish an infection (Ratledge \& Dover, 2000). The ability to obtain iron from free haem or haem proteins from the host tissues constitutes an important source of iron for many bacterial pathogens (Genco \& Dixon, 2001; Osorio \& Lemos, 2002). However, one of the main strategies to obtain iron is the synthesis and secretion of $\mathrm{Fe}$ (III)

Abbreviations: A domain, adenylation domain; ArCP, aryl-carrier protein; DAHP, 3-deoxy-D-arabino-heptulosonate-7-phosphate; HPI, highpathogenicity island; NRPS, non-ribosomal peptide synthetase; SSH, suppression subtractive hybridization.

The GenBank/EMBL/DDBJ accession number for the sequences reported in this paper is AJ699306. chelators, named siderophores, which are low molecular mass iron-chelating molecules that can remove iron from host iron-binding proteins (Crosa, 1989) and then enter the cell through outer-membrane receptor proteins. Many siderophores are small peptides synthesized by nonribosomal peptide synthetases (NRPSs), which are multimodular enzymes that produce peptide products of a particular sequence without an RNA template (Crosa \& Walsh, 2002; Schwarzer et al., 2003).

Iron acquisition has been widely recognized as a determinant of bacterial virulence (Braun, 2005). Thus, it is not surprising that several iron-transport systems have been described as part of horizontally transmitted elements, showing differential occurrence in pathogenic vs nonpathogenic strains. The siderophore aerobactin genes are found on plasmids in certain strains of Escherichia coli and Salmonella (Williams, 1979; Colonna et al., 1985), but have been described to constitute a chromosomal pathogenicity 
island in Shigella flexneri strains (Vokes et al., 1999). Similarly, highly pathogenic strains of Yersinia (Yersinia enterocolitica 1B, Yersinia pseudotuberculosis I and Yersinia pestis) harbour a large chromosomal fragment termed the high-pathogenicity island (HPI), which is absent from lowpathogenic and avirulent strains (Carniel et al., 1996). The Yersinia HPI carries a cluster of genes involved in the biosynthesis, transport and regulation of the siderophore yersiniabactin and is integrated in the chromosomal asntRNA gene (Buchrieser et al., 1998). It consists of a $30.5 \mathrm{~kb}$ highly conserved functional core region and a 5-13 kb ATrich variable part (Rakin et al., 1999). The core region comprises genes for the biosynthesis (irp1-irp5 and irp9) and uptake (irp6-irp 8 and $f y u A$ ) of the siderophore, as well as an AraC-like regulator $(y b t A)$. An integrase gene (int $B$ ) is found at the upstream end of the HPI. Specific studies conducted with mutant strains have demonstrated the importance of the yersiniabactin system in the virulence of Y. enterocolitica (Rakin et al., 1994), Y. pestis (Bearden et al., 1997) and Y. pseudotuberculosis (Carniel et al., 1992). Although first identified in Yersinia spp., the HPI has been also described in several genera of Enterobacteriaceae (Schubert et al., 1998; Bach et al., 2000; Olsson et al., 2003).

Photobacterium damselae subsp. piscicida was initially isolated from a massive fish mortality in Chesapeake Bay, and the disease was named pasteurellosis after the classification of this agent as Pasteurella piscicida (Janssen \& Surgalla, 1968). The pathogen was later reassigned to the genus Photobacterium as Photobacterium damselae subsp. piscicida, sharing species epithet with $P$. damselae subsp. damselae (formerly Vibrio damsela) (Gauthier et al., 1995) and thus constituting a new member of the family Vibrionaceae. P. damselae subsp. piscicida is one of the most devastating bacterial pathogens in marine aquaculture, due to its wide geographical distribution, host range and massive mortality (Magariños et al., 1996a). The virulence of this micro-organism is believed to be a multifactorial process not yet fully understood. The major virulence factor so far identified is a plasmid-encoded protein, AIP56, which induces apoptosis in fish macrophages and neutrophils (do Vale et al., 2005). It is also believed that polysaccharide capsular material constitutes a main virulence factor (Magariños et al., 1996b). This bacterium is able to obtain iron from haemin and haemoglobin as unique iron sources in vitro (Magariños et al., 1994), and a genetic system for haem uptake has been recently described (Juiz-Río et al., 2005a). A gene encoding the ferric uptake regulator (Fur) protein has been identified in this species, and it is believed to act as an iron-dependent transcriptional repressor regulating genes involved in iron uptake (Juiz-Río et al., 2004; Osorio et al., 2004). It was reported that strains of this subspecies can efficiently obtain iron from human transferrin, and this is achieved by a mechanism involving the production of siderophores (Magariños et al., 1994). However, the nature of this siderophore is still unknown and the genes involved in its biosynthesis have not been characterized, although preliminary chemical assays and bioassays indicated that it is neither a catechol nor a hydroxamate (Magariños et al., 1994).

This study was undertaken to obtain an insight into the genetic basis of the siderophore-mediated iron-uptake system of $P$. damselae subsp. piscicida, to study its role in virulence for fish and to assess if genetic differences exist among $P$. damselae subspecies and strains.

\section{METHODS}

Bacteria, plasmids and media. Bacterial strains and plasmids used in this study are listed in Table 1. P. damselae subsp. piscicida and $P$. damselae subsp. damselae strains were routinely grown at $25^{\circ} \mathrm{C}$ in either Tryptic Soy Agar or Tryptic Soy Broth (Difco) supplemented with $1 \% \mathrm{NaCl}$ (TSA-1 and TSB-1, respectively), and in CM9 minimal medium (Mouriño et al., 2004). E. coli strains were grown at $37^{\circ} \mathrm{C}$ in Luria-Bertani (LB) broth or LB agar, as well as in CM9 minimal medium, supplemented with antibiotics when appropriate. Y. enterocolitica strains were grown at $37^{\circ} \mathrm{C}$ in $\mathrm{LB}$, Nutrient Broth (NB) and Nutrient Agar (NBA). All strains were stored frozen at $-80{ }^{\circ} \mathrm{C}$ in $\mathrm{LB}$ broth with $20 \%$ glycerol. Antibiotics were used at the following final concentrations: kanamycin (Kan) at $25 \mu \mathrm{g} \mathrm{ml}{ }^{-1}$; ampicillin sodium salt (Amp) at $50 \mu \mathrm{g} \mathrm{ml}^{-1}$; chloramphenicol (Cam) at $20 \mu \mathrm{g} \mathrm{ml}^{-1}$; rifampicin (Rif) at $50 \mu \mathrm{g} \mathrm{ml}^{-1}$. All stocks were filter-sterilized and stored at $-20^{\circ} \mathrm{C}$. The iron chelator $2,2^{\prime}-$ dipyridyl (Sigma) was prepared at $10 \mathrm{mM}$ in water.

Suppression subtractive hybridization (SSH). Bacterial genome subtraction was performed using the PCR-Select Bacterial Genome Subtraction Kit (Clontech), as previously described (Juiz-Río et al., 2005b). In brief, tester (DI21) and driver strain (RM71) genomic DNA $(2 \mu \mathrm{g})$ were each digested with 10 units RsaI for $5 \mathrm{~h}$. The tester DNA was aliquoted into two tubes, and each was ligated to a different adaptor provided with the kit. Two hybridization rounds were carried out: in the first hybridization, an excess of driver DNA was added to each adaptor-ligated tester DNA, and samples were then heat denatured and allowed to anneal. In the second hybridization round, the two samples from the first hybridization were mixed together without denaturation. The product of this last hybridization was then used as a template in a PCR reaction to amplify the testerspecific sequences, using Advantage cDNA polymerase mix (Clontech). The obtained PCR products were cloned into the pGEM-T Easy vector (Promega) and recombinant clones were screened by restriction analysis prior to DNA sequencing.

Recombinant DNA techniques, DNA sequencing and data analysis. Recombinant DNA methods were performed following standard protocols (Sambrook \& Russell, 2001). Chromosomal DNA was isolated using the Easy-DNA kit (Invitrogen). Plasmid purification and elution of DNA fragments from agarose gels were performed using kits from Qiagen. Southern blot analysis was performed with Hybond-N + membranes (Amersham Biosciences), using the ECL Direct Nucleic Acid labelling and detection system (Amersham Biosciences) and following the manufacturer's instructions. PCR reactions were carried out using the Expand Long Template kit (Roche). For inverse PCR, chromosomal DNA was digested with a single restriction enzyme, the fragments self-ligated and the ligation products subsequently used as templates in PCR reactions with suitable primers. DNA sequences were determined by the dideoxy chain-termination method using the CEQ DTCS-Quick Start Kit (Beckman Coulter) using a capillary DNA sequencer CEQ 8000 (Beckman Coulter). Comparison of the sequence data with published sequences in EMBL/GenBank was performed with the BLAST software via the internet (http://www.ncbi.nlm.nih.gov/blast and http://www.ebi.ac.uk/blast/index.html). Prediction of protein 
Table 1. Strains and plasmids

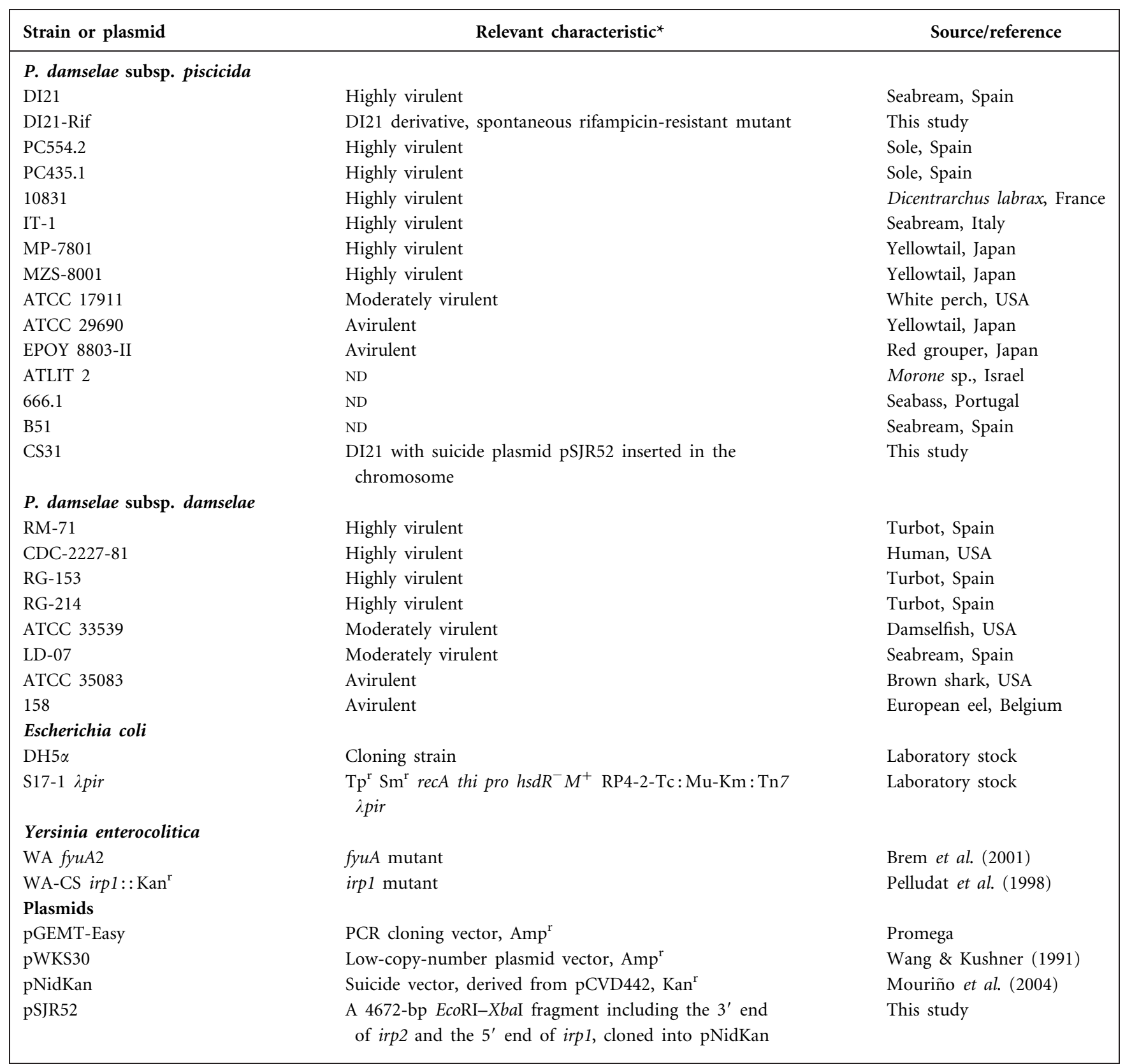

*Virulence data for fish obtained from Magariños et al. (1992) and Osorio et al. (2000); ND, not determined.

domains was carried out by using the Pfam database online facilities (http://www.sanger.ac.uk/Software/Pfam/). Putative transcriptional terminators were predicted using RNAMotif (Macke et al., 2001).

RNA isolation and RT-PCR. $P$. damselae subsp. piscicida DI21 was grown in TSB-1 and then subcultured on CM9 minimal medium. Total RNA was prepared from mid-exponential-phase cultures using the RNAwiz Isolation Reagent (Ambion), according to the manufacturer's instructions. RNA preparations were then subjected to standard treatments with RNase-free DNase I. Reverse transcription reaction was performed by using the M-MLV reverse transcriptase (Invitrogen). For each reaction, $1 \mu \mathrm{g}$ total RNA was used.
Subsequent PCR amplification was carried out with Taq polymerase (Bioline) using suitable primers. As negative controls, DNA contamination of the RNA samples was ruled out by PCR using Taq DNA polymerase without reverse transcriptase. As positive controls, each primer combination was tested in PCR reactions carried out using chromosomal DNA as template.

Protein analysis. $P$. damselae subsp. piscicida DI21 and CS31 and $P$. damselae subsp. damselae RM71 cells were grown in CM9 supplemented with either $\mathrm{FeCl}_{3} 10 \mu \mathrm{M}$ or 2,2'-dipyridyl $60 \mu \mathrm{M}$ (iron-sufficient and iron-restricted conditions, respectively). This concentration of $2,2^{\prime}$-dipyridyl was lowered to $30 \mu \mathrm{M}$ in the case of 
the DI21 irp1 mutant strain (CS31). Cells were centrifuged and total membrane proteins were obtained as previously described (Toranzo et al., 1983). Protein concentration was adjusted for all the samples, and proteins were separated by SDS-PAGE. The protein bands were visualized by staining with Coomassie brilliant blue.

Construction of an irp1-targeted disruptant of $\boldsymbol{P}$. damselae subsp. piscicida. An EcoRI-XbaI fragment of $4672 \mathrm{bp}$, which included $\sim 1500 \mathrm{bp}$ of the irp2 downstream end and $\sim 3100 \mathrm{bp}$ of the irp1 upstream end (Fig. 1a), was ligated into vector pWKS30. The DNA insert was further excised with NotI-SalI and ligated into the suicide vector pNidKan (Mouriño et al., 2004), to generate pSJR52. As a pCVD442 derivative, pNidKan contains R6K ori, requiring the pir gene product for replication. Insertion of the suicide vector into the chromosome by a single crossover results in a $\mathrm{Kan}^{\mathrm{R}}$ phenotype. The pSJR52 plasmid was transformed into E. coli S17-1 $\lambda$ pir followed by mobilization into DI21-Rif. Insertional mutants were selected on agar plates containing kanamycin $\left(50 \mu \mathrm{g} \mathrm{ml}^{-1}\right)$ and rifampicin $\left(50 \mu \mathrm{g} \mathrm{ml}^{-1}\right)$, and presence of the inserted plasmid into the irpl gene was confirmed by Southern hybridization (data not shown).

Assay methods for siderophore production, growth under iron-limiting conditions, and virulence experiments. Production of siderophores by $P$. damselae subsp. piscicida DI21-Rif and its irp1 disruptant CS31 was tested by the universal chemical assay of Schwyn \& Neilands (1987) in solid medium. The assay was performed by spotting $20 \mu \mathrm{l}$ supernatant of each bacterial culture, previously grown in CM9, onto chrome azurol S (CAS) agar plates. The ability of $P$. damselae subsp. piscicida strains to grow under conditions of iron limitation was evaluated by using CM9 minimal medium, in the presence of $60 \mu \mathrm{M} 2,2^{\prime}$-dipyridyl (Sigma).

The pathogenicity of $P$. damselae subsp. piscicida DI21-Rif and CS31 strains for turbot (Scophthalmus maximus) was assayed using 10 fish (mean weight $15 \mathrm{~g}$ ) per dose, as previously described (Magariños et al., 1992). Fish were inoculated with bacterial doses ranging from $10^{3}$ to $10^{7}$ cells. Mortalities were recorded daily for 10 days, and the $\mathrm{LD}_{50}$ was calculated according to Magariños et al. (1992).

Cross-feeding assays. Cross-feeding assays were utilized to test the ability of $Y$. enterocolitica and $P$. damselae subsp. piscicida strains to induce the growth of the same strains subjected to iron starvation. Two mutants of $Y$. enterocolitica that were deficient in the biosynthesis of yersiniabactin (strain WA-CS $\operatorname{irp} 1:: \operatorname{Kan}^{\mathrm{r}}$ ), or in the yersiniabactin receptor (strain WA fyuA2), respectively, were used. $P$. damselae subsp. piscicida CS31 was used for detection of yersiniabactin utilization. One hundred microlitres of overnight cultures of each indicator strain was added to $3 \mathrm{ml}$ molten TSA-1 ( $P$. damselae subsp. piscicida strains) or NBA ( $Y$. enterocolitica

(a)

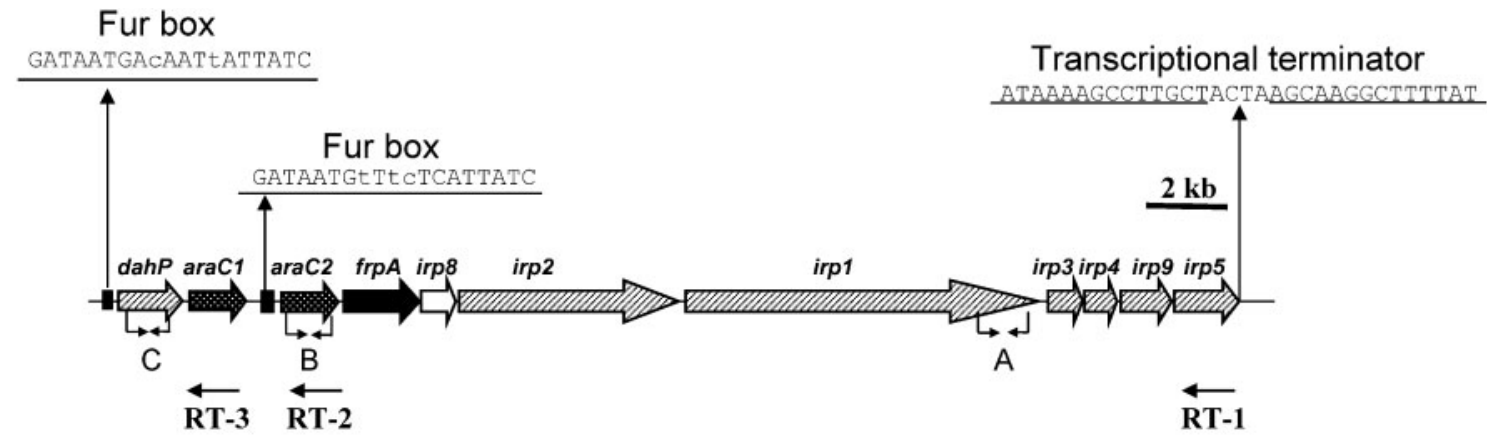

(b)

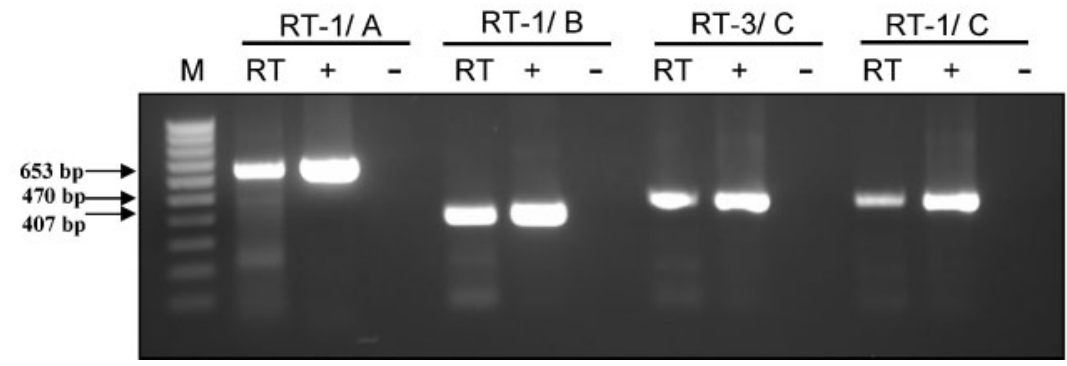

Fig. 1. (a) Physical map of the siderophore biosynthesis and transport gene cluster of $P$. damselae subsp. piscicida DI21, and primer design for RT-PCR operon mapping. ORFs are depicted as arrows, which indicate the direction of transcription. Predicted functions of the gene products are indicated as follows: dahp, irp2, irp1, irp3, irp4, irp9 and irp5, biosynthetic genes; frp4, outer-membrane receptor; $a r a C 1$ and araC2, transcriptional activators; irp8, putative inner-membrane siderophore exporter. RT-1, RT-2 and RT-3 are the primers used in reverse transcription. Arrow pairs located on top of $\mathrm{A}, \mathrm{B}$ and $\mathrm{C}$ letters denote primer pairs used in the subsequent PCR reactions. Predicted Fur boxes identified in dahP and araC2 putative promoters are shown. A palindromic region downstream of the stop codon of irp5 constitutes a potential transcriptional terminator. (b) Operon mapping: results of PCR amplifications (RT) carried out with primer pairs A, B and C using as template the products of RT reactions obtained with primers RT-1, RT-2 and RT-3. M, molecular size marker (100 bp). Results indicate that a transcript originating from dahP putative promoter reaches the end of irp5 gene. Negative controls $(-)$ are PCR reactions without reverse transcriptase. Positive controls $(+)$ are PCR reactions using chromosomal DNA as a template. 
strains) and plated onto appropriate prepoured TSA or NBA plates supplemented with $200 \mu \mathrm{M} 2,2^{\prime}$-dipyridyl. Sterile filter-paper discs were loaded with $10 \mu \mathrm{l}$ of cultures of different strains previously grown in TSC-1 ( $P$. damselae subsp. piscicida) or NB (Y. enterocolitica) supplemented with 60 and $100 \mu \mathrm{M} 2,2^{\prime}$-dipyridyl, respectively, to induce siderophore production. Discs loaded with $10 \mu \mathrm{l}$ yersiniabactin $\left(0 \cdot 1 \mathrm{mg} \mathrm{ml}^{-1}\right)$ were also tested. Results were scored as positive or negative after $48 \mathrm{~h}$ incubation. Yersiniabactin was purchased from EMC microcollections $\mathrm{GmbH}$.

\section{RESULTS}

\section{Isolation of DNA fragments specific to $P$. damselae subsp. piscicida DI21 using SSH}

P. damselae subsp. damselae RM71 is known to produce a hydroxamate (Fouz et al., 1997). However, siderophore assays specific for catechols or hydroxamates did not detect the siderophore produced by $P$. damselae subsp. piscicida DI21 (Magariños et al., 1994). We hypothesized that the production of different types of siderophore would be due to a differential gene content between these two strains. Therefore, we carried out SSH in order to isolate DNA fragments encountered uniquely in DI21 (tester strain), but absent from RM71 (driver strain). Some of the subtracted clones contained DNA sequences encoding transposases, tRNA hydroxylases and hypothetical proteins (to be published elsewhere). One clone, pSSH1, contained a $\sim 1500$ bp insert that encoded a 508 amino acid partial protein with significant similarity $(63 \%)$ to the $Y$. enterocolitica high molecular mass protein 2 (HMWP2) (Table 2), a member of the family of the NRPSs involved in the synthesis of siderophore yersiniabactin. Based on this homology, this $P$. damselae subsp. piscicida gene was named irp2. Southern blot hybridization demonstrated that the DNA fragment cloned in pSSH1 was absent from the driver strain, RM71 (data not shown).

We hypothesized that the $P$. damselae subsp. piscicida DI21 irp2 gene could be part of a gene cluster involved in siderophore biosynthesis. The DNA insert of clone pSSH1 was used as a probe to screen blots of DI21 chromosomal DNA digested with various enzymes, and was found to hybridize to a $\sim 9 \mathrm{~kb} \mathrm{XbaI-XbaI} \mathrm{DNA} \mathrm{fragment} \mathrm{(data} \mathrm{not} \mathrm{shown).} \mathrm{This}$ DNA fragment was further cloned into pGEM-T Easy and sequenced to completion and the complete sequence of irp2 was established as an ORF encoding a protein of 1979 aa with a predicted molecular mass of $221 \mathrm{kDa}$. Inverse PCR was used to amplify additional DNA segments upstream and downstream of irp2, which were cloned and sequenced to completion. A gene cluster (irp cluster) spanning $35 \mathrm{~kb}$ and including 11 ORFs was thus identified (Fig. 1a).

\section{Predicted protein sequences}

Homologues of the proteins encoded by the irp cluster predicted ORFs are summarized in Table 2. The first ORF, dahP, encodes a putative 3-deoxy-D-arabino-heptulosonate-7-phosphate (DAHP) synthase. It showed the highest similarity with a DAHP synthase of Vibrio vulnificus.
Homologues of this enzyme are responsible for the condensation of the pentose phosphate pathway intermediate D-erythrose 4-phosphate and the glycolytic pathway intermediate phosphoenolpyruvate to DAHP, a step in the biosynthesis of chorismate. The second and third genes of this cluster were termed $a r a C 1$ and $a r a C 2$, respectively. The closest relatives of $\mathrm{AraC} 1$ and $\mathrm{AraC} 2$ proteins were putative AraC-family transcriptional regulators of Photobacterium profundum and Vibrio cholerae RC385. Homologues also included putative transcriptional regulators of other bacterial species, but the homology was restricted to the C-terminus. A protein domain prediction by using the Pfam database identified a helix-turn-helix motif within approximately the last 100 residues of the C-terminus of the deduced AraC1 and AraC2 proteins (data not shown), which is a conserved domain typical of this family of regulators. Interestingly, AraC2 showed similarity to YbtA, a transcriptional activator that controls expression of genes within the Yersinia HPI (Fetherston et al., 1996; Anisimov et al., 2005).

The fourth ORF of the cluster was termed frpA, encoding a predicted 660 amino acid protein that showed significant similarity with the $Y$. pestis and Pseudomonas fluorescens yersiniabactin and quinolobactin outer-membrane receptors, respectively. The fifth ORF, irp 8, encodes a protein that showed homology to putative proteins whose function has not been ascertained in any species. A search conducted using the COG database (http://www.ncbi.nlm.nih.gov/ COG) placed this protein within the group of permeases of the major facilitator superfamily (MFS). Similarity was found between this protein and YbtX, a highly hydrophobic cytoplasmic membrane protein encoded in the Yersinia HPI (Fetherston et al., 1999). Its subcellular location and the similarity to MFS proteins suggest that Irp8 could be involved in siderophore export.

The sixth ORF of the cluster corresponds to the irp2 gene, isolated by subtractive hybridization between strains DI21 and RM71 (see above). The seventh ORF was termed irp1; its start codon was located $50 \mathrm{bp}$ downstream of the stop codon of $\operatorname{irp2}$. Irp1 is a protein of 3996 aa, with a predicted molecular mass of $442 \mathrm{kDa}$. The first $\mathrm{N}$-terminal 430 aa of Irp1 show homology to typical PKS (polyketide synthase) domains, and the identity percentage in this region was $62 \%$ to Y. enterocolitica HMWP1.

The eighth ORF was termed irp3; it encodes a protein with homology to thiazolinyl reductase components of the siderophore yersiniabactin biosynthesis pathway (YbtU component) (Miller et al., 2002). The protein encoded by the ninth ORF, Irp4, was found to be $43 \%$ and $41 \%$ identical to $Y$. pestis YbtT and $Y$. enterocolitica Irp4, respectively, described as thioesterase-like proteins involved in yersiniabactin biosynthesis (Geoffroy et al., 2000; Pelludat et al., 1998), and $36 \%$ identical to a thioesterase-like protein located in the anguibactin biosynthetic gene cluster of Vibrio anguillarum (Farrell et al., 1990). 
Table 2. Proteins with homology to products of $P$. damselae subsp. piscicida DI21 genes of the siderophore biosynthesis cluster described in this study (asterisks denote that homology is restricted to the last 100 residues of the protein)

\begin{tabular}{|c|c|c|c|}
\hline P. damselae protein (no. of aa) & EMBL/GenBank no. & Identity (\%) & Similarity $(\%)$ \\
\hline \multicolumn{4}{|l|}{ DAHP synthase (354) } \\
\hline V. vulnificus DAHP synthase & Q8D5S3 & 54 & 68 \\
\hline Escherichia coli phospho-2-dehydro-3-deoxyheptonate aldolase & Q8FIY4 & 51 & 67 \\
\hline V. cholerae El Tor N16961 phospho-2-dehydro-3-deoxyheptonate aldolase & Q9KRX6 & 50 & 64 \\
\hline Y. pseudotuberculosis phospho-2-dehydro-3-deoxyheptonate aldolase & Q66A12 & 53 & 68 \\
\hline \multicolumn{4}{|l|}{ AraC1 (327) } \\
\hline P. profundum hypothetical transcriptional regulator, AraC family & Q6LRJ3 & 59 & 75 \\
\hline V. cholerae RC385 AraC-type protein & ZP_00753343 & 58 & 77 \\
\hline Ralstonia solanacearum probable transcription regulator & Q8XYE5 & $35^{\star}$ & $56^{*}$ \\
\hline Ps. syringae transcriptional regulator, AraC family & Q882M0 & $35^{*}$ & $61^{*}$ \\
\hline \multicolumn{4}{|l|}{$\operatorname{AraC2}(323)$} \\
\hline P. profundum hypothetical transcriptional regulator, AraC family & Q6LRJ4 & 63 & 77 \\
\hline V. cholerae RC385 AraC-type DNA-binding domain-containing protein & ZP_00753342 & 60 & 77 \\
\hline Bacteroides fragilis putative AraC family transcriptional regulatory protein & Q5LHP7 & $41^{*}$ & $61^{*}$ \\
\hline Y. enterocolitica AraC family transcriptional regulator $\mathrm{YbtA}$ & Q9X9I4 & $34^{*}$ & $54^{*}$ \\
\hline \multicolumn{4}{|l|}{ FrpA $(660)$} \\
\hline P. profundum hypothetical outer membrane receptor & Q6LRJ5 & 65 & 81 \\
\hline V. cholerae RC385 outer membrane receptor protein & ZP_00753341 & 65 & 81 \\
\hline Ph. luminescens putative ferrisiderophore receptor FyuA & Q7N4L5 & 40 & 60 \\
\hline Y. enterocolitica yersiniabactin receptor & P46360 & 26 & 46 \\
\hline Ps. fluorescens quinolobactin receptor & Q84HG2 & 25 & 42 \\
\hline \multicolumn{4}{|l|}{ Irp8 $(412)$} \\
\hline P. profundum hypothetical protein & Q6LRJ6 & 57 & 75 \\
\hline V. cholerae RC385 putative permease of the major facilitator superfamily & ZP_00753340 & 57 & 74 \\
\hline Ph. luminescens hypothetical protein & Q7N4L4 & 41 & 61 \\
\hline E. coli putative cytoplasmic transmembrane protein & Q8FGF7 & 35 & 52 \\
\hline Y. enterocolitica $\operatorname{Irp} 8$ protein & Q9X9I7 & 32 & 49 \\
\hline \multicolumn{4}{|l|}{ Irp2 (1979) } \\
\hline P. profundum hypothetical NRPS & Q6LRJ7 & 55 & 70 \\
\hline V. cholerae RC385 NRPS & ZP_00753339 & 56 & 70 \\
\hline Ph. luminescens HMWP2-like protein & Q7N4L1 & 47 & 63 \\
\hline Ps. syringae yersiniabactin NRPS & Q48HQ4 & 47 & 61 \\
\hline Y. pestis yersiniabactin biosynthetic protein HMWP2 & Q97399 & 45 & 61 \\
\hline Y. enterocolitica yersiniabactin biosynthetic protein HMWP2 & P48633 & 45 & 61 \\
\hline \multicolumn{4}{|l|}{ Irp1 (3996) } \\
\hline P. profundum putative beta-ketoacyl synthase & Q6LRJ8 & 50 & 67 \\
\hline V. cholerae RC385 polyketide synthase & ZP_00753338 & 52 & 66 \\
\hline Ph. luminescens HMWP1-like protein & Q7N4L0 & 45 & 60 \\
\hline Ps. syringae yersiniabactin polyketide/NRPS & Q882M6 & 51 & 64 \\
\hline Y. pestis yersiniabactin biosynthetic protein HMWP1 & Q3V8D5 & 50 & 63 \\
\hline Y. enterocolitica HMWP1 & O54511 & 49 & 62 \\
\hline \multicolumn{4}{|l|}{ Irp3 (361) } \\
\hline V. cholerae RC385, oxidoreductase & ZP_00753422 & 61 & 74 \\
\hline P. profundum putative reductase component & Q6LRK0 & 59 & 76 \\
\hline Ps. syringae yersiniabactin synthetase, thiazolinyl reductase component & Q882M7 & 44 & 62 \\
\hline$Y$. pestis thiazolinyl-S-HMWP1 reductase (YbtU) & Q8D0C4 & 42 & 59 \\
\hline Y. enterocolitica yersiniabactin biosynthetic protein Irp3 & O54512 & 42 & 59 \\
\hline \multicolumn{4}{|l|}{ Irp4 (233) } \\
\hline P. profundum hypothetical thioesterase & Q6LRK1 & 60 & 77 \\
\hline V. cholerae RC385 predicted thioesterase & ZP_00753421 & 53 & 62 \\
\hline Ph. luminescens hypothetical protein similar to $Y$. enterocolitica Irp4 & Q7N4K8 & 50 & 62 \\
\hline Y. pestis yersiniabactin biosynthetic protein $\mathrm{YbtT}$ & Q7BS79 & 43 & 56 \\
\hline Y. enterocolitica yersiniabactin biosynthetic protein Irp4 & O54513 & 41 & 57 \\
\hline
\end{tabular}


Table 2. cont.

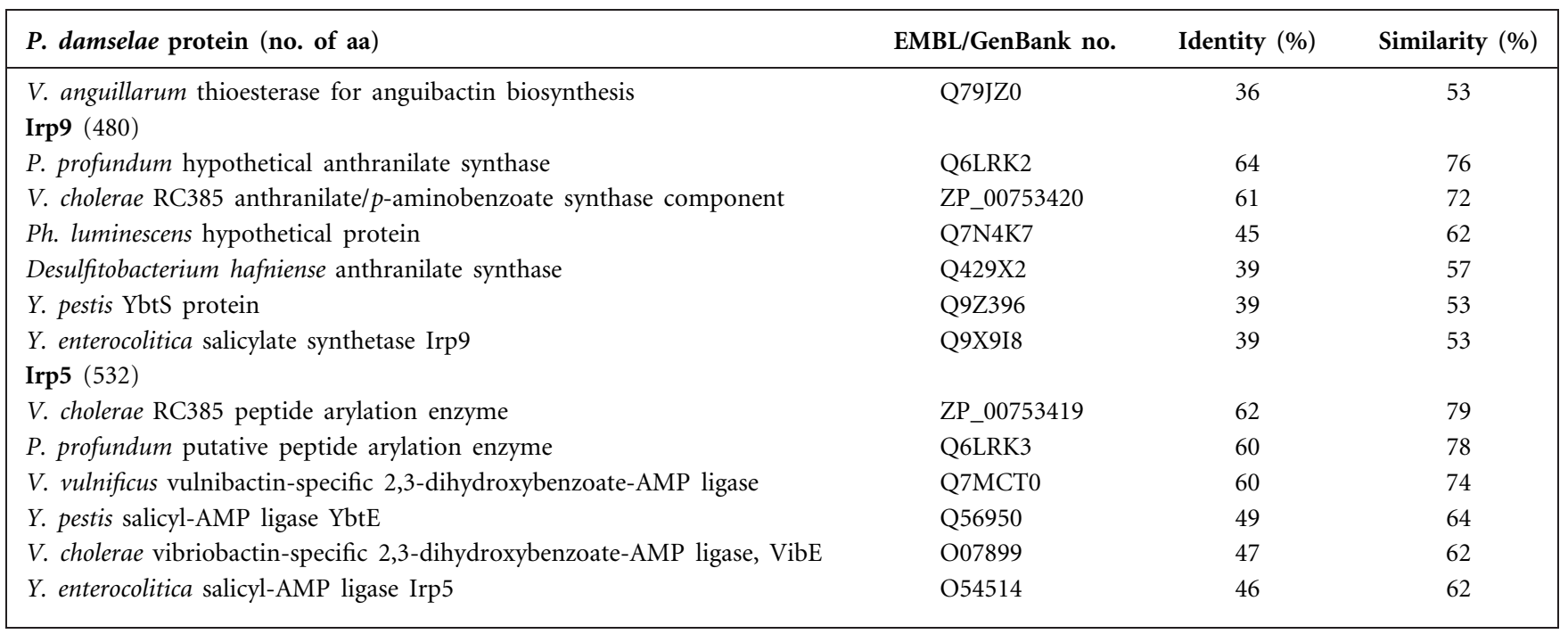

The tenth ORF encodes a protein which we termed Irp9. It is similar to $Y$. enterocolitica Irp9, an enzyme that directly converts chorismate into salicylate, which is further used as a precursor in the synthesis of yersiniabactin (Pelludat et al., 2003). Irp5, encoded by the eleventh ORF, was found to be homologous to a series of aryl-activating enzymes, involved in the adenylation and activation of aryl groups and amino acids. It is $47 \%$ identical to $Y$. pestis YbtE, a salicyl-AMP ligase which activates salicylic acid and transfers the activated molecule to the first ArCP (aryl-carrier protein) domain of the non-ribosomal peptide synthetase HMWP2 (Gehring et al., 1998). Interestingly, Irp5 is $44 \%$ identical to $V$. cholerae VibE, the vibriobactin-specific 2,3-dihydroxybenzoate-AMP ligase, the enzyme that adenylates and activates 2,3-dihydroxybenzoate, a precursor of vibriobactin (Wyckoff et al., 1997).

\section{Transcriptional organization of the cluster}

The 11 genes of the cluster described in this study have the same transcriptional polarity. Downstream of irp5 is an ORF with opposite transcriptional polarity to the 11-gene cluster described and its predicted protein product shows similarity to putative inner-membrane ATPases (data not shown). Upstream of $d a h P$ we sequenced 3 additional $\mathrm{kb}$, but no ORFs were found.

Sequence analysis identified a conserved putative Furbinding site (Fur box), upstream of dahP gene, which shares 17 out of 19 identical nucleotides with the E. coli Fur-box consensus sequence. Similarly, a potential Fur box with identity in 16 of 19 positions with the consensus was found upstream of araC2 (Fig. 1a). This would suggest the existence of at least two iron-regulated promoters within this cluster. To study the transcriptional organization of the cluster, we conducted a series of reverse-transcriptase reactions with primers targeted to the downstream ends of irp5 (RT-1), araC2 (RT-2) and $\operatorname{araC1}$ (RT-3), and subsequent $\mathrm{PCR}$ reactions were performed with three different primer combinations, A, B and C, that amplified internal fragments of irp1 (653 bp), araC2 (407 bp) and dahP (470 bp), respectively (Fig. 1a). All the reactions yielded a product of the expected size, and negative and positive controls (see Methods) corroborated the accuracy of the RT-PCR results (Fig. 1b). These results demonstrate that the 11 genes of the cluster described in this study can be co-transcribed from the promoter upstream of dahP, although the existence of additional promoters, particularly upstream of $\operatorname{araC2}$, cannot be ruled out. When we applied the RNAMotif program, a unique transcriptional stop was predicted, starting at $18 \mathrm{bp}$ downstream of the irp5 stop codon (Fig. 1a). No additional transcriptional terminators were predicted within this gene cluster.

\section{Presence of iron-regulated high molecular mass proteins in $P$. damselae subsp. piscicida DI21}

The presence of Fur-binding sequences similar to the E. coli consensus upstream of $d a h P$ and araC2 would suggest that iron concentration plays a role in regulating the expression of genes within the irp cluster. $P$. damselae subsp. piscicida DI21 cells were grown in iron-rich and iron-limited media, and the profiles of total membrane proteins were compared. As a result, two high molecular mass protein bands were observed when the cells were cultured in iron-restricted media, whereas these bands were not observed under conditions of iron sufficiency (Fig. 2). The molecular masses of these two proteins likely correspond to those predicted for the $\operatorname{Irp} 1(442 \mathrm{kDa})$ and $\operatorname{Irp} 2(221 \mathrm{kDa})$ as described above, encoded by the irp cluster. These two protein bands were absent under both iron-limiting and iron-sufficient conditions in the P. damselae subsp. damselae strain RM71, which was used as the driver strain in the SSH experiment described above. Although the subcellular 


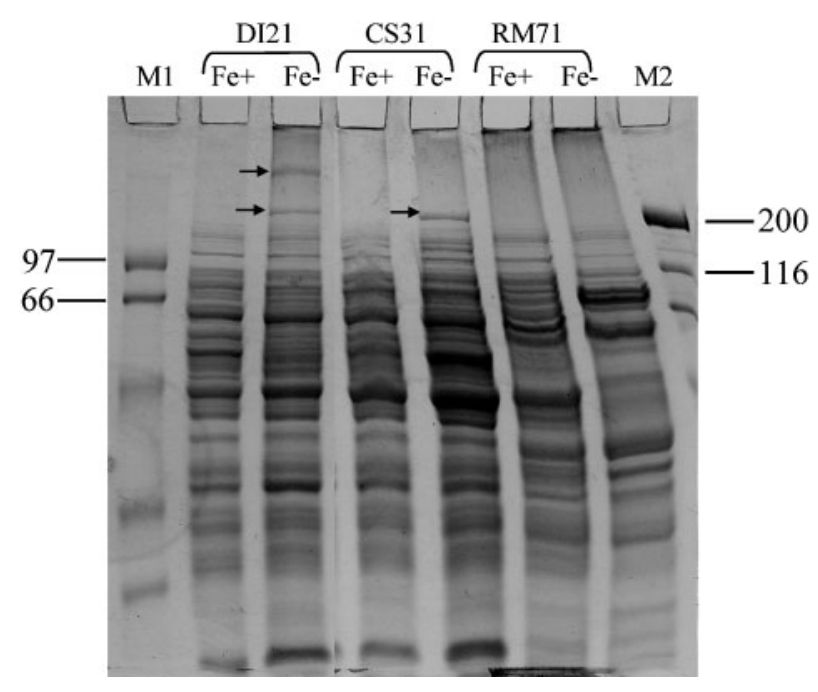

Fig. 2. Total membrane proteins purified from $P$. damselae subsp. piscicida DI21, $P$. damselae subsp. piscicida CS31 mutant and $P$. damselae subsp. damselae RM71 under conditions of iron excess $(\mathrm{Fe}+)$ and iron limitation $(\mathrm{Fe}-)$. M1 and M2 are molecular mass markers, and numbers at side denote $\mathrm{kDa}$. Arrows denote bands corresponding to the iron-regulated Irp1 and Irp2 proteins.

location of Irp1 and Irp2 homologues is not well known, there is some evidence that they may contain hydrophobic domains that may be membrane associated (Guilvout et al.,
1993) and this could explain the purification of these proteins in the membrane fraction.

\section{Irp1, Irp2 and Irp5 are putative members of the NRPS family}

Most of the bacterial siderophores described to date are synthesized by NRPSs (Crosa \& Walsh, 2002), which are modularly organized multi-enzyme complexes that represent at the same time template and biosynthetic machinery (Schwarzer et al., 2003). Using the Pfam database, we found that the predicted domain organizations of the $P$. damselae subsp. piscicida Irp5, Irp2 and Irp1 proteins are highly similar to those predicted for the $Y$. enterocolitica Irp5, HMWP2 and HMWP1 proteins. However, subsp. piscicida Irp2 lacks an ArCP domain, which is otherwise encountered at the N-terminus of Y. enterocolitica HMWP2. Interestingly, Irp1 is larger than HMWP1 and contains different domains (Fig. 3).

The adenylation (A) domains are responsible for substrate recognition and activation as acyl-adenylate derivatives. It has been reported that the substrate specificity of the A domains is mostly determined by ten residues of the substrate-binding pocket and these residues can be considered as the codons of non-ribosomal peptide synthesis (Stachelhaus et al., 1999; Schwarzer et al., 2003). Thus, it is possible to predict the substrates that will be recognized and adenylated by the three A domains predicted in this study: one in Irp5, and one in each of Irp2 and

\author{
Y. enterocolitica $\operatorname{Irp} 5$ \\ P. damselae Irp5 \\ Y. enterocolitica HMWP2 \\ P. damselae Irp2
}

Y. enterocolitica HMWP1

P. damselae Irp1

\section{$\mathrm{A}^{\text {Sal }}$}

$\mathrm{A}^{\text {Sal }}$ 
Table 3. Selectivity-conferring amino acids in the adenylation domains of $P$. damselae subsp. piscicida Irp1, Irp2 and Irp5 NRPSs

Prediction of the substrate specificity according to the non-ribosomal code, and comparative alignment with the respective positions of the substrate-binding pocket described in A domains of Y. enterocolitica HMWP2 and YbtE, and in V. anguillarum AngR. Positions refer to the B. brevis GrsA (gramicidin S synthetase). Cys, cysteine; Sal, salicylate.

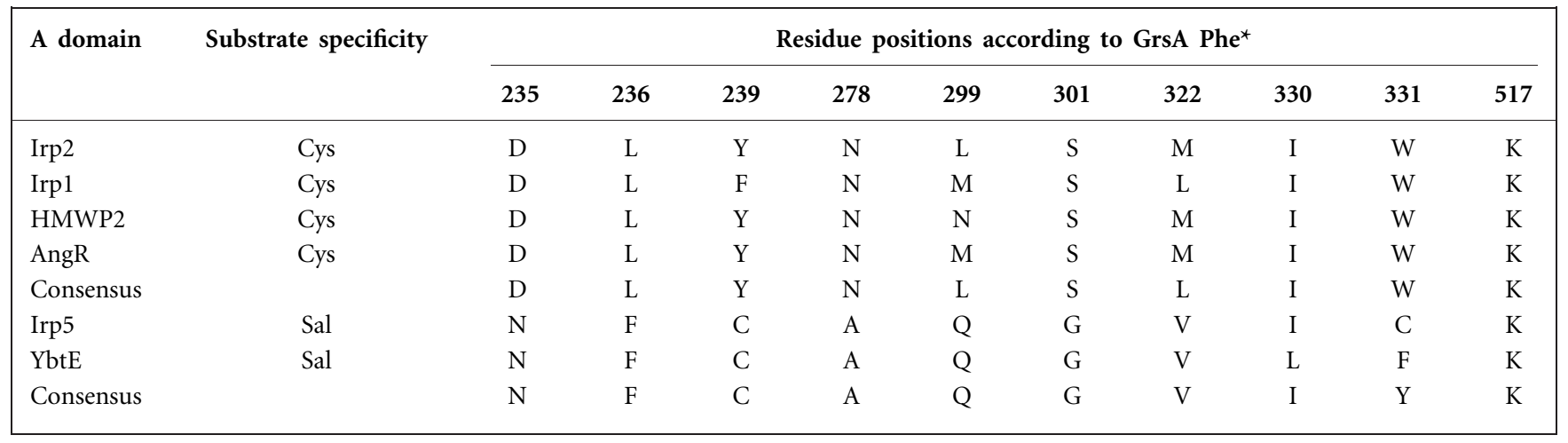

${ }^{*}$ Stachelhaus et al. (1999).

Irp1. We carried out a sequence alignment of these three predicted A domains with that of the gramicidin $S$ synthetase (GrsA) from Bacillus brevis and determined the ten conserved residues of the substrate-binding pocket. As shown in Table 3, the Irp5 A domain is predicted to select salicylate, thus having the same substrate specificity as $Y$. enterocolitica Irp5. On the other hand, the A domains of Irp2 and Irp1 are predicted to select and activate cysteine, which is the same substrate as the homologous A domain present in $Y$. enterocolitica HMWP2.

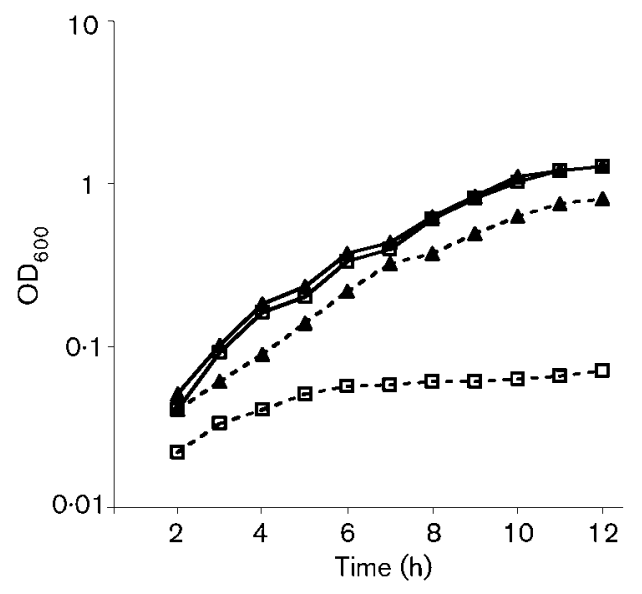

Fig. 4. Growth of DI21-Rif parental strain ( $\mathbf{\Delta})$, and CS31 mutant $(\square)$ in $\mathrm{CM} 9$ minimal medium supplemented with $10 \mu \mathrm{M}$ $\mathrm{FeSO}_{4}$ (iron-sufficient conditions; continuous lines), and in CM9 in the presence of the iron chelator 2,2'-dipyridyl at a concentration of $60 \mu \mathrm{M}$ (iron-limited conditions; discontinuous lines).

\section{irp1 insertional inactivation renders $\boldsymbol{P}$. damselae subsp. piscicida unable to produce siderophores and to grow under iron-limiting conditions, and decreases the virulence for fish}

In order to demonstrate that the irp gene cluster identified in this study is involved in siderophore biosynthesis in $P$. damselae subsp. piscicida DI21, an operon disruption was constructed by inserting a suicide plasmid in the $\operatorname{irp} 1$ gene. The irp1 insertional mutant, which was termed CS31, was tested on CAS agar plates and found to be CAS negative, indicating loss of siderophore production. When we selected for a second cross that eliminated the suicide plasmid and restored the wild-type gene, the strain recovered the ability to produce siderophores, demonstrating that loss of siderophore production was due to irp1 insertional mutation (data not shown).

Parental and mutant strains showed a similar growth in CM9 minimal medium supplemented with $10 \mu \mathrm{M} \mathrm{FeSO} 4$ (iron-sufficient conditions) (Fig. 4). The same strains were grown in CM9 in the presence of the iron chelator 2,2' dipyridyl at a concentration of $60 \mu \mathrm{M}$. Under these ironlimiting conditions, the irp insertional mutant CS31 was impaired for growth with respect to the parental strain (Fig. 4). In addition, when the protein profiles of CS31 and the parental strain, under both iron-sufficient and ironlimiting conditions, were compared, the mutant lacked the high molecular mass iron-regulated protein believed to correspond to Irp1 (Fig. 2).

To analyse the role of siderophore-mediated iron uptake in the virulence of $P$. damselae subsp. piscicida for fish, we carried out experimental inoculations with the parental strain DI21-Rif and the CS31 mutant in turbot fingerlings. The $\mathrm{LD}_{50}$ obtained with the CS31 mutant $\left(2.6 \times 10^{7}\right.$ 
Table 4. Results of the cross-feeding assays performed with different $P$. damselae subsp. piscicida and $Y$. enterocolitica strains and with purified yersiniabactin

\begin{tabular}{|c|c|c|c|c|}
\hline \multirow[t]{3}{*}{ Tester } & \multicolumn{4}{|c|}{ Ability to be cross-fed } \\
\hline & \multicolumn{2}{|c|}{ P. damselae subsp. piscicida } & \multicolumn{2}{|c|}{ Y. enterocolitica } \\
\hline & DI21 & CS31 & WA $f y u A 2$ & WA-CS $\operatorname{irp} 1:: \operatorname{Kan}^{\mathrm{r}}$ \\
\hline Yersiniabactin & + & + & - & + \\
\hline DI21 & + & + & - & + \\
\hline CS31 & - & - & - & - \\
\hline WA fyuA2 & + & + & - & + \\
\hline WA-CS $\operatorname{irp} 1:: \operatorname{Kan}^{\mathrm{r}}$ & - & - & - & - \\
\hline
\end{tabular}

bacterial cells per fish) was $\sim 100$-fold higher than with the parental strain $\left(8 \times 10^{5}\right)$, demonstrating that production of siderophores mediated by the irp cluster contributes significantly to the virulence of $P$. damselae subsp. piscicida for fish.

\section{Cross-feeding assays}

Based on protein-domain sequence predictions, the siderophore synthesized by $P$. damselae subsp. piscicida might be similar to yersiniabactin. To assess this possibility, $P$. damselae subsp. piscicida DI21 and CS31, and Y. enterocolitica fyuA and irp1 mutants, were cultured under ironlimiting conditions and the ability of the different strains as well as of purified yersiniabactin to induce the growth of the indicator strains was evaluated. The cross-feeding assays showed that $Y$. enterocolitica WA $f y u A 2$, which produces yersiniabactin but lacks the yersiniabactin FyuA receptor, is able to cross-feed both P. damselae subsp. piscicida DI21 and CS31, whereas Y. enterocolitica WA-CS $\operatorname{irp} 1:: \operatorname{Kan}^{\mathrm{r}}$, which has the yersiniabactin FyuA receptor but is unable to synthesize yersiniabactin, is not (Table 4). The assays using purified yersiniabactin corroborated that both the parental P. damselae subsp. piscicida and the CS31 mutant are able to use this siderophore (Table 4).

We also tested if the $P$. damselae subsp. piscicida DI21 siderophore can stimulate the growth of $Y$. enterocolitica strains subjected to iron starvation. The results showed that P. damselae subsp. piscicida DI21 can promote the growth of $Y$. enterocolitica irp1 but not that of $Y$. enterocolitica fyuA, demonstrating that the siderophore produced by $P$. damselae subsp. piscicida can efficiently be used by $Y$. enterocolitica and this growth promotion is dependent on the presence of the functional outer-membrane yersiniabactin receptor FyuA. On the other hand, P. damselae subsp. piscicida CS31 could not cross-feed any of the indicator strains (Table 4). This indicates that induction of growth in Yersinia strains by $P$. damselae subsp. piscicida is actually due to the production of a siderophore molecule whose synthesis is dependent on the irp gene cluster. Altogether, these results suggest that the siderophore produced by subsp. piscicida could be structurally and functionally related to yersiniabactin.

\section{Distribution of irp cluster genes in $P$. damselae subsp. piscicida and subsp. damselae isolates}

The presence of genes of the irp cluster described in this study in various $P$. damselae isolates of the two subspecies and with diverse isolation origins was tested by Southern hybridization. Chromosomal DNA samples were digested with HindIII, and Southern blotting was individually performed with probes internal to the dahP, araC1, frpA, irp2, irp1, irp9 and irp5 genes. For all the hybridization probes, the results were equivalent: all these genes were found to be absent in all the subsp. damselae strains and were present uniquely in subsp. piscicida strains DI21, B51, 666.1, PC554.2, PC435.1 and ATLIT 2 (Fig. 5). Interestingly, the two subsp. piscicida avirulent strains (EPOY 8803-II and ATCC 29690) tested negative for all these genes (Fig. 5). All the positive strains are recognized as virulent for fish (Table 1) and were isolated in Spain and Portugal, with the exception of ATLIT 2, which was isolated in Israel. When the primer pairs used to amplify the DNA probes were also used in a PCR-based screening with all the strains, the data for the presence of irp cluster genes were equivalent to those obtained by Southern blotting (data not shown).

\section{Similarity to gene clusters of other species: the Yersinia HPI}

We searched DNA sequence databases of both complete and incomplete bacterial genome projects to find homologues of the $P$. damselae subsp. piscicida siderophore biosynthesis gene cluster. The highest similarity in sequence and gene arrangement of the $P$. damselae cluster corresponds to a region of the $P$. profundum SS9 genome (Vezzi et al., 2005). This DNA region contains homologues of all the $P$. damselae subsp. piscicida genes, with the exception of dahP (Fig. 6). Although the P. profundum PBPRA1666 gene, which is annotated as a putative AMP-binding enzyme, does not have a gene counterpart in subsp. piscicida, it encodes a protein that is highly homologous to the C-terminus of $P$. damselae subsp. piscicida Irp1, suggesting that the subsp. piscicida Irp1 protein is actually the counterpart of the P. profundum proteins Irp1 and PBPRA1666. None of the published Vibrio genomes was shown to contain a gene cluster homologous to that described in this study (Heidelberg et al., 2000; Chen et al., 2003; Makino et al., 


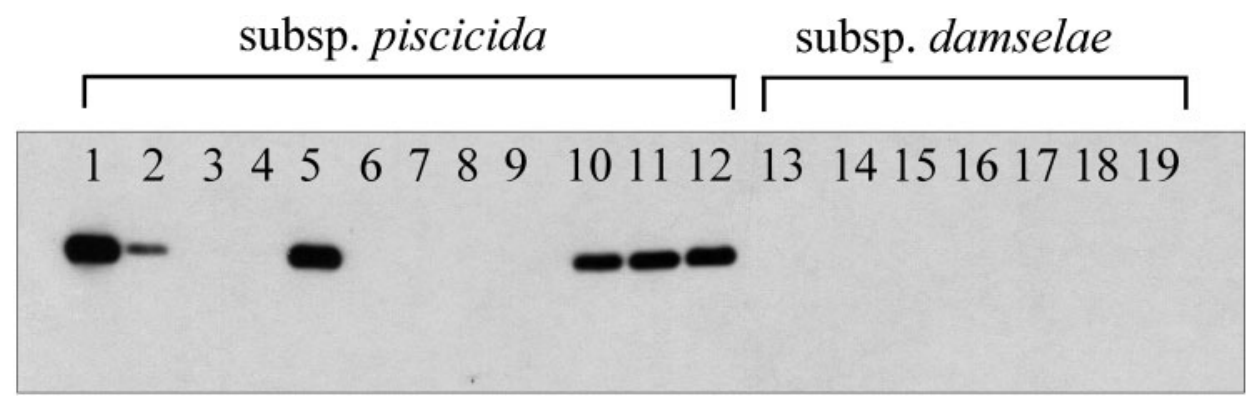

Fig. 5. Results of Southern hybridization screening for the presence of irp1 gene, using Hindlll-digested chromosomal DNA from a collection of $P$. damselae strains. Similar results were obtained with $d a h P, \operatorname{araC} 1, \operatorname{frp} A, \operatorname{irp} 2, \operatorname{irp} 9$ and irp5 probes (results not shown). Lanes 1-12, P. damselae subsp. piscicida strains DI21, B51, ATCC 17911, ATCC 29690, 666.1, 10831, MP-7801, EPOY 8803-II, MZS-8001, PC554.2, PC435.1 and ATLIT 2. Lanes 13-19, P. damselae subsp. damselae strains RM-71, ATCC 33539, ATCC 35083, CDC 2227-81, RG-214, LD-07 and 158.

2003; Ruby et al., 2005). However, we identified genes similar to those of the $P$. damselae subsp. piscicida irp cluster in V. cholerae RC385 (GenBank ref. AAKH00000000), a strain whose genome project is being completed at TIGR (The Institute for Genomic Research, http://www.tigr.org/). Interestingly, these genes are distributed into two gene clusters separated by approximately $75 \mathrm{~kb}$ (Fig. 6).

The 11-gene cluster described in this work shows similarity with the HPI of Y. enterocolitica. The HPI contains homologues of all the $P$. damselae subsp. piscicida genes described here, with the exception of $d a h P$ and araC1. However, the arrangement of genes differs between the two species
(Fig. 6), and whereas the Yersinia HPI contains genes that are divergently transcribed, the $P$. damselae subsp. piscicida genes are all transcribed from the same DNA strand.

\section{DISCUSSION}

Previous studies reported that $P$. damselae subsp. piscicida strains produce a siderophore which is different from that synthesized by isolates of $P$. damselae subsp. damselae (Magariños et al., 1994; Fouz et al., 1997). The genetic content can vary considerably between strains of the same species, and this variation is particularly frequent in genes

\section{Y. enterocolitica}

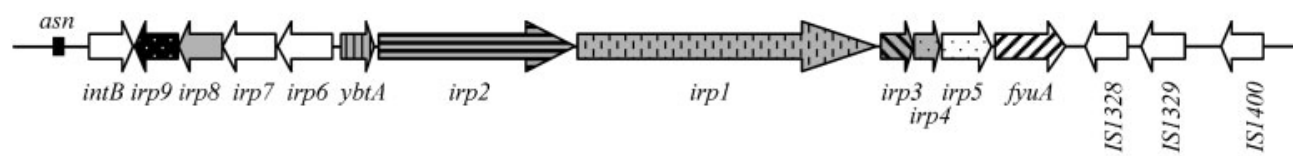

P. profundum

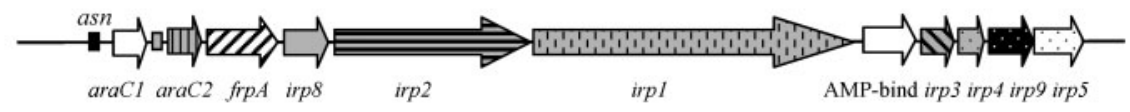

P. damselae

subsp. piscicida

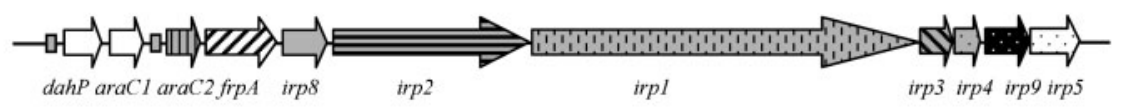

V. cholerae $\mathrm{RC} 385$

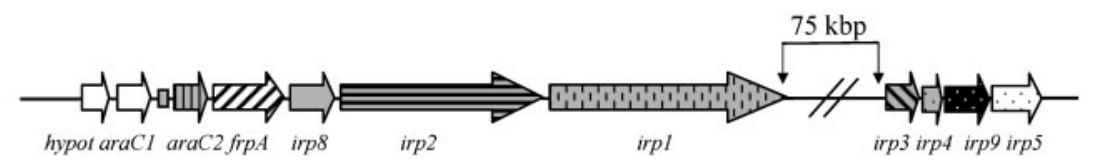

3000 aa

Fig. 6. Comparative analysis of gene arrangement in the $P$. damselae subsp. piscicida DI21 siderophore biosynthesis and transport gene cluster, and related clusters in Yersinia enterocolitica HPI, Photobacterium profundum and Vibrio cholerae RC385. For clarity and for comparative purposes, the same gene nomenclature of $P$. damselae subsp. piscicida genes was applied to the $P$. profundum and $V$. cholerae RC385 homologues. The small grey squares denote potential Fur-binding sites (Fur boxes). 
that encode virulence factors. In this scenario, SSH has been successfully applied to the identification of genomic differences between bacterial strains (Winstanley, 2002), and it has been recently applied to the assessment of genetic diversity among $P$. damselae subsp. piscicida isolates (JuizRío et al., 2005b). In the present study, by using SSH, we have identified a subsp. piscicida-specific gene cluster spanning $\sim 35 \mathrm{~kb}$, involved in siderophore biosynthesis. This cluster includes 11 putative ORFs that can be cotranscribed from a promoter upstream of dahP. However, we understand that this does not exclude the possibility that additional promoter sequences may exist upstream of other genes of this cluster.

The Fur protein is the major repressor of iron-uptake systems in Gram-negative bacteria, repressing transcription of the genes and thus limiting the entry of excess iron into the cell (Escolar et al., 1999). Two high molecular mass protein bands, which are predicted to correspond to Irp1 and Irp2 encoded within the irp cluster, are induced under conditions of iron limitation, which could be explained by the presence of Fur-binding sequences predicted upstream of dahP and araCl. In accordance with this, previous studies demonstrated that $P$. damselae subsp. piscicida DI21 harbours a fur homologue that can act as an iron-dependent transcriptional repressor (Juiz-Río et al., 2004; Osorio et al., 2004).

Genes involved in siderophore biosynthesis can also be subject to transcriptional activation. The $\mathrm{AraC} 1$ and $\mathrm{AraC} 2$ proteins described in this study are putative members of the AraC family of transcriptional activators, which are classified based on a conserved 99 aa stretch usually found within the $\mathrm{C}$-terminus. This conserved region is predicted to encode two helix-turn-helix motifs that function in DNA binding (Gallegos et al., 1997). The homology of AraCl and AraC2 with other proteins in databases was shown to be restricted to the $\mathrm{C}$-terminus, indicating that the main variability resides within the $\mathrm{N}$-terminus. Interestingly, there is increasing evidence that the N-terminus of AraCfamily activators regulating siderophore synthesis and transport genes contains cofactor-binding regions, and this co-factor has proved to be the cognate ferri-siderophore complex (Tanabe et al., 2005; Michel et al., 2005). It is also interesting that $\mathrm{AraC} 2$ shows similarity to $\mathrm{YbtA}$, a protein that controls expression of yersiniabactin synthesis genes within the Yersinia spp. HPI in a yersiniabactin-dependent manner (Fetherston et al., 1996; Anisimov et al., 2005). It is noteworthy that Yersinia irp1 mutants do not produce HMWP1 and HMWP2 (Pelludat et al., 1998), since yersiniabactin is required for upregulation of irp genes. In contrast, we have demonstrated here that a $P$. damselae subsp. piscicida irp1 mutant still produces irp2 (Fig. 2). These results suggest that differences in gene regulation exist between Yersinia and P. damselae subsp. piscicida gene clusters, and either AraC1, AraC2 or both could play a regulatory role distinct from YbtA. In this context, we could not find predicted YbtA-binding sites in the putative promoter regions of $d a h P$ and $A r a C 2$ (data not shown).
FrpA is the putative outer-membrane siderophore receptor of $P$. damselae subsp. piscicida DI21. It shows high similarity to the yersiniabactin receptor FyuA and to the quinolobactin receptor of Ps. fluorescens, but not to any of the siderophore receptors described in vibrios, suggesting that $P$. damselae subsp. piscicida might utilize a siderophore that is not related to any of the catecholate- or hydroxamate-type siderophores described to date in other vibrios.

The insertional inactivation of the irp cluster led to an impairment of growth under conditions of iron limitation, suggesting that this cluster encodes a siderophore-based mechanism that is crucial for iron uptake. The absence of reaction in the CAS agar plates of the CS31 mutant indicates that this is the only high-affinity iron-scavenging system present in $P$. damselae subsp. piscicida DI21. The irp1 mutant displayed reduced virulence in fish, demonstrating that the presence of this siderophore-mediated ironacquisition mechanism contributes significantly to the virulence of $P$. damselae subsp. piscicida. The high $\mathrm{LD}_{50}$ exhibited by the mutant strain $\left(2 \cdot 6 \times 10^{7}\right)$ could even be due to LPS toxicity, which would mean that the siderophore mutant could be avirulent. Mutants in the irpl gene of extraintestinal pathogenic E. coli carrying HPI were also less virulent than the parental strain (Schubert et al., 2002). The connection between siderophore-mediated iron-acquisition mechanisms and bacterial virulence is well established (Faraldo-Gómez \& Sanson, 2003), and recent studies have demonstrated the importance of siderophore production in the virulence of fish pathogens (Stork et al., 2004; Fernández et al., 2004).

Protein sequence comparisons suggested that the siderophore produced by $P$. damselae subsp. piscicida is synthesized by an NRPS-mediated mechanism similar to that described for yersiniabactin. Based on the in silico analysis, the as yet uncharacterized siderophore produced by P. damselae subsp. piscicida DI21 might contain at least one salicylate and two cysteine residues in its structure. The dahPencoded DAHP synthase is probably involved in the synthesis of chorismate. This is an intermediate in the biosynthesis of aromatic compounds, some of which are precursors of aromatic carboxy and amino acids which are part of the structure of siderophores. In this context, a dahP homologue has been described as part of the gene cluster involved in siderophore anguibactin biosynthesis in $V$. anguillarum (Alice et al., 2005). Irp9 is the candidate enzyme to be involved in the synthesis of salicylate, based on its high similarity to the Y. enterocolitica Irp9. Irp3 and Irp4 are counterparts of the Yersinia spp. Irp3 (or YbtU) and Irp4 (or YbtT). Therefore, the $P$. damselae subsp. piscicida gene cluster described in this study contains all the gene counterparts of the yersiniabactin biosynthetic complex (Crosa \& Walsh, 2002). All these data suggest that the DI21 siderophore might be structurally related to yersiniabactin (Drechsel et al., 1995), and this hypothesis is supported by the results obtained in the cross-feeding assays. However, the differences in the domain composition between the 
Yersinia and DI21 Irp1 and Irp2 homologues suggest that the two siderophores could have some differences in their structures.

The gene cluster described in this study was found to be absent in subsp. damselae strains, but was present in subsp. piscicida strains isolated from Spain and Portugal and one isolate from Israel. The two subsp. piscicida avirulent strains as well as all the isolates from Japan lacked this system, although they have been reported to produce siderophores (Magariños et al., 1994). This suggests that these strains harbour an as yet uncharacterized genetic system for siderophore production. In a previous study (Magariños et al., 2000), it was proposed that two distinct clonal lineages exist within $P$. damselae subsp. piscicida, represented by the European isolates on the one hand, and the Japanese isolates on the other hand. Our data support this hypothesis and indicate that DNA fragments from the operon described here could be used as genetic markers for the epidemiological typing of strains of this fish pathogen.

As $P$. damselae subsp. piscicida is a member of the Vibrionaceae, it is expected that the genes responsible for siderophore biosynthesis in this species would show high similarity to homologous genes in other vibrios. However, most of the predicted protein sequences encoded by this gene cluster did not show significant similarity to described siderophore synthesis and transport gene clusters of the Vibrionaceae. Homologous gene clusters exist in $P$. profundum SS9 and V. cholerae RC385, although their role in siderophore biosynthesis remains untested. It is noteworthy that the $P$. profundum irp homologues are located downstream of an asn-tRNA gene (Fig. 6), which suggests that this gene cluster may have been integrated in the chromosome in a similar way as described for the Yersinia HPI. Although we did not find evidence of asn-tRNA genes upstream of the $P$. damselae subsp. piscicida irp cluster, this does not exclude the possibility that this cluster is part of a laterally transmitted integrating element, since genetic rearrangements of the flanking sequences could have occurred after integration, or a mechanism of integration independent of the presence of tRNA genes could have taken place. In this context, no tRNA genes were found in the $V$. cholerae RC385 homologous cluster.

Among the gene clusters showing homology to the irp cluster of $P$. damselae subsp. piscicida, the Yersinia HPI is the most widely studied. The HPI is widespread among both pathogenic and non-pathogenic taxa of Enterobacteriaceae (Schubert et al., 1998; Bach et al., 2000; Olsson et al., 2003) and its ability to be horizontally transmitted has recently been demonstrated (Lesic \& Carniel, 2005). The similarity between HPI genes and those described here in the irp cluster suggests that the $P$. damselae subsp. piscicida siderophore biosynthesis genes might have a common evolutionary origin with the Yersinia HPI. Recently, gene clusters similar to the Yersinia HPI have also been described in yersiniabactin-producing strains of Pseudomonas syringae and Photorhabdus luminescens (Bultreys et al., 2006), providing more clues about the evolution and dispersion of yersiniabactin-related genes.

The differential occurrence of this gene cluster among $P$. damselae strains, together with its low similarity to siderophore synthesis genes of other vibrios, suggest that the $P$. damselae subsp. piscicida siderophore biosynthesis gene cluster could have been acquired by horizontal transfer. Future studies will help to ascertain whether the irp cluster is part of a genomic island and if this DNA region can be mobilized in a similar way as that described for the HPI.

\section{ACKNOWLEDGEMENTS}

We thank J. Heesemann and A. Rakin for providing Y. enterocolitica strains, and K. E. Klose for helpful suggestions and useful comments. This work was supported by grants AGL2003-00086 and AGL200600697 from the Ministry of Education and Science of Spain (grants cofunded by the FEDER Programme from the European Union) and grant PGIDIT04PXIC23501PN from Xunta de Galicia to M.L.L.; S. J. R. also thanks the Spanish Ministry of Education and Science for a Predoctoral Fellowship.

\section{REFERENCES}

Alice, A. F., Lopez, C. S. \& Crosa, J. H. (2005). Plasmid- and chromosome-encoded redundant and specific functions are involved in biosynthesis of the siderophore anguibactin in Vibrio anguillarum 775: a case of chance and necessity? J Bacteriol 187, 2209-2214.

Anisimov, R., Brem, D., Heesemann, J. \& Rakin, A. (2005). Molecular mechanism of YbtA-mediated transcriptional regulation of divergent overlapping promoters $y b t A$ and irp6 of Yersinia enterocolitica. FEMS Microbiol Lett 250, 27-32.

Bach, S., de Almeida, A. \& Carniel, E. (2000). The Yersinia highpathogenicity island is present in different members of the family Enterobacteriaceae. FEMS Microbiol Lett 183, 289-294.

Bearden, S. W., Fetherston, J. D. \& Perry, R. D. (1997). Genetic organization of the yersiniabactin biosynthetic region and construction of avirulent mutants in Yersinia pestis. Infect Immun 65, 16591668.

Braun, V. (2005). Bacterial iron transport related to virulence. Contrib Microbiol 12, 210-233.

Brem, D., Pelludat, C., Rakin, A., Jacobi, C. A. \& Heesemann, J. (2001). Functional analysis of yersiniabactin transport genes of Yersinia enterocolitica. Microbiology 147, 1115-1127.

Buchrieser, C., Brosch, R., Bach, S., Guiyoule, A. \& Carniel, E. (1998). The high-pathogenicity island of Yersinia pseudotuberculosis can be inserted into any of the three chromosomal asn tRNA genes. Mol Microbiol 30, 965-978.

Bultreys, A., Gheysen, I. \& de Hoffmann, E. (2006). Yersiniabactin production by Pseudomonas syringae and Escherichia coli, and description of a second yersiniabactin locus evolutionary group. Appl Environ Microbiol 72, 3814-3825.

Carniel, E., Guiyoule, A., Guilvout, I. \& Mercereau-Puijalon, 0. (1992). Molecular cloning, iron-regulation and mutagenesis of the irp2 gene encoding HMWP2, a protein specific for the highly pathogenic Yersinia. Mol Microbiol 6, 379-388.

Carniel, E., Guilvout, I. \& Prentice, M. (1996). Characterization of a large chromosomal "high-pathogenicity island" in biotype 1B Yersinia enterocolitica. J Bacteriol 178, 6743-6751. 
Chen, C. Y., Wu, K. M., Chang, Y. C. \& 12 other authors (2003). Comparative genome analysis of Vibrio vulnificus, a marine pathogen. Genome Res 13, 2577-2587.

Colonna, B., Nicoletti, M., Visca, P., Casalino, M., Valenti, P. \& Maimone, F. (1985). Composite IS1 elements encoding hydroxamate-mediated iron uptake in F1me plasmids from epidemic Salmonella spp. J Bacteriol 162, 307-316.

Crosa, J. H. (1989). Genetics and molecular biology of siderophore mediated iron transport in bacteria. Microbiol Rev 53, 517-530.

Crosa, J. H. \& Walsh, C. T. (2002). Genetics and assembly line enzymology of siderophore biosynthesis in bacteria. Microb Mol Biol Rev 66, 223-249.

Do Vale, A., Silva, M. T., dos Santos, N. M. S., Nascimento, D. S., Reis-Rodrigues, P., Costa-Ramos, C., Ellis, A. E. \& Azevedo, J. E. (2005). AIP56, a novel plasmid-encoded virulence factor of Photobacterium damselae subsp. piscicida with apoptogenic activity against sea bass macrophages and neutrophils. Mol Microbiol 58, $1025-1038$.

Drechsel, H., Stephan, H., Lotz, R., Haag, H., Zahner, H., Hantke, K. \& Jung, G. (1995). Structural elucidation of yersiniabactin, a siderophore from highly virulent Yersinia strains. Liebigs Ann 10, 1727-1733.

Escolar, L., Pérez-Martín, J. \& de Lorenzo, V. (1999). Opening the iron box: transcriptional metalloregulation by the Fur protein. J Bacteriol 181, 6223-6229.

Faraldo-Gómez, J. \& Sanson, M. S. P. (2003). Acquisition of siderophores in gram-negative bacteria. Nat Rev 4, 105-116.

Farrell, D. H., Mikesell, P., Actis, L. A. \& Crosa, J. H. (1990). A regulatory gene, angR, of the iron uptake system of Vibrio anguillarum: similarity with phage $\mathrm{P} 22$ cro and regulation by iron. Gene 86, 45-51.

Fernández, L., Márquez, I. \& Guijarro, J. A. (2004). Identification of specific in vivo-induced (ivi) genes in Yersinia ruckeri and analysis of ruckerbactin, a catecholate siderophore iron acquisition system. Appl Environ Microbiol 70, 5199-5207.

Fetherston, J. D., Bearden, S. W. \& Perry, R. D. (1996). YbtA, an AraC-type regulator of the Yersinia pestis pesticin/yersiniabactin receptor. Mol Microbiol 22, 315-325.

Fetherston, J. D., Bertolino, V. J. \& Perry, R. D. (1999). YbtP and YbtQ: two ABC transporters required for iron uptake in Yersinia pestis. Mol Microbiol 32, 289-299.

Fouz, B., Biosca, E. G. \& Amaro, C. (1997). High affinity iron-uptake systems in Vibrio damsela: role in the acquisition of iron from transferrin. J Appl Microbiol 82, 157-167.

Gallegos, M. T., Schleif, R., Bairoch, A., Hofmann, K. \& Ramos, J. L. (1997). AraC/XylS family of transcriptional regulators. Microbiol Mol Biol Rev 61, 393-410.

Gauthier, G., Lafay, B., Ruimy, R., Breittmayer, V., Nicolas, J. L., Gauthier, M. \& Christen, R. (1995). Small-subunit rRNA sequences and whole DNA relatedness concur for the reassignment of Pasteurella piscicida (Snieszko et al.) Janssen and Surgalla to the genus Photobacterium as Photobacterium damselae subsp. piscicida comb. nov. Int J Syst Bacteriol 45, 139-144.

Gehring, A. M., DeMoll, E., Fetherston, J. D., Mori, I., Mayhew, G. F., Blattner, F., Walsh, C. \& Perry, R. (1998). Iron acquisition in plague: molecular logic in the biosynthesis of yersiniabactin by Yersinia pestis. Chem Biol 5, 573-586.

Genco, C. A. \& Dixon, D. W. (2001). Emerging strategies in microbial haem capture. Mol Microbiol 39, 1-11.

Geoffroy, V. A., Fetherston, J. D. \& Perry, R. D. (2000). Yersinia pestis $\mathrm{YbtU}$ and $\mathrm{YbtT}$ are involved in synthesis of the siderophore yersiniabactin but have different effects on regulation. Infect Immun 68, 4452-4461.

Guilvout, I., Mercereau-Puijalon, O., Bonnefoy, S., Pugsley, A. P. \& Carniel, E. (1993). High-molecular-weight protein 2 of Yersinia enterocolitica is homologous to AngR of Vibrio anguillarum and belongs to a family of proteins involved in nonribosomal peptide synthesis. J Bacteriol 175, 5488-5504.

Heidelberg, J. F., Eisen, J. A., Nelson, W. C. \& 29 other authors (2000). DNA sequence of both chromosomes of the cholera pathogen Vibrio cholerae. Nature 406, 477-483.

Janssen, W. A. \& Surgalla, M. J. (1968). Morphology, physiology, and serology of a Pasteurella species pathogenic for white perch (Roccus americanus). J Bacteriol 96, 1606-1610.

Juiz-Río, S., Osorio, C. R. \& Lemos, M. L. (2004). Identification and characterisation of the fur genes in Photobacterium damselae ssp. piscicida and ssp. damselae. Dis Aquat Organ 58, 151-156.

Juiz-Río, S., Osorio, C. R. \& Lemos, M. L. (2005a). Heme uptake genes in human and fish isolates of Photobacterium damselae: existence of hutA pseudogenes. Arch Microbiol 183, 347-358.

Juiz-Río, S., Osorio, C. R., de Lorenzo, V. \& Lemos, M. L. (2005b) Subtractive hybridization reveals a high genetic diversity in the fish pathogen Photobacterium damselae subsp. piscicida: evidence of a SXT-like element. Microbiology 151, 2659-2669.

Lesic, B. \& Carniel, E. (2005). Horizontal transfer of the highpathogenicity island of Yersinia pseudotuberculosis. J Bacteriol 187, 3352-3358.

Macke, T. J., Ecker, D. J., Gutell, R. R., Gautheret, D., Case, D. A. \& Sampath, R. (2001). RNAMotif, an RNA secondary structure definition and search algorithm. Nucleic Acids Res 29, 4724-4735.

Magariños, B., Santos, Y., Romalde, J. L., Rivas, C., Barja, J. L. \& Toranzo, A. E. (1992). Pathogenic activities of the live cells and extracellular products of the fish pathogen Pasteurella piscicida. J Gen Microbiol 138, 2491-2498.

Magariños, B., Romalde, J. L., Lemos, M. L., Barja, J. L. \& Toranzo, A. E. (1994). Iron uptake by Pasteurella piscicida and its role in pathogenicity for fish. Appl Environ Microbiol 60, 2990-2998.

Magariños, B., Toranzo, A. E. \& Romalde, J. L. (1996a). Phenotypic and pathobiological characteristics of Pasteurella piscicida. Annu Rev Fish Dis 6, 41-64.

Magariños, B., Bonet, R., Romalde, J. L., Martínez, M. J., Congregado, F. \& Toranzo, A. E. (1996b). Influence of the capsular layer on the virulence of Pasteurella piscicida for fish. Microb Pathog 21, 289-297.

Magariños, B., Toranzo, A. E., Barja, J. L. \& Romalde, J. L. (2000). Existence of two geographically-linked clonal lineages in the bacterial fish pathogen Photobacterium damselae subsp. piscicida evidenced by random amplified polymorphic DNA analysis. Epidemiol Infect 125, 213-219.

Makino, K., Oshima, K., Kurokawa, K. \& 14 other authors (2003). Genome sequence of Vibrio parahaemolyticus: a pathogenic mechanism distinct from that of $V$. cholerae. Lancet 361, 743-749.

Michel, L., González, N., Jagdeep, S., Nguyen-Ngoc, T. \& Reimmann, C. (2005). PchR-box recognition by the AraC-type regulator PchR of Pseudomonas aeruginosa requires the siderophore pyochelin as an effector. Mol Microbiol 58, 495-509.

Miller, D. A., Luo, L., Hillson, N., Keating, T. A. \& Walsh, C. T. (2002). Yersiniabactin synthetase: a four-protein assembly line producing the nonribosomal peptide/polyketide hybrid siderophore of Yersinia pestis. Chem Biol 9, 333-344.

Mouriño, S., Osorio, C. R. \& Lemos, M. L. (2004). Characterization of the heme uptake cluster genes in the fish pathogen Vibrio anguillarum. I Bacteriol 186, 6159-6167. 
Olsson, C., Olofsson, T., Ahrné, S. \& Molin, G. (2003). The Yersinia HPI is present in Serratia liquefaciens isolated from meat. Lett Appl Microbiol 37, 275-280.

Osorio, C. R. \& Lemos, M. L. (2002). Haem iron acquisition mechanisms in Vibrionaceae. In Recent Research Developments in Microbiology, vol. 6, pp. 419-436. Edited by S. G. Pandalai. Research Signpost, Kerala, India.

Osorio, C. R., Romalde, J. L., Barja, J. L. \& Toranzo, A. E. (2000). Presence of phospholipase-D $(d l y)$ gene coding for damselysin production is not a pre-requisite for pathogenicity in Photobacterium damselae subsp. damselae. Microb Pathog 28, 119-126.

Osorio, C. R., Lemos, M. L. \& Braun, V. (2004). Identification of Fur regulated genes in the bacterial fish pathogen Photobacterium damselae subsp. piscicida using the Fur titration assay. Biometals 17, 725-733.

Pelludat, C., Rakin, A., Jacobi, C. A., Schubert, S. \& Heesemann, J. (1998). The yersiniabactin biosynthetic gene cluster of Yersinia enterocolitica: organization and siderophore-dependent regulation. J Bacteriol 180, 538-546.

Pelludat, C., Brem, D. \& Heesemann, J. (2003). Irp9, encoded by the high-pathogenicity island of Yersinia enterocolitica, is able to convert chorismate into salicylate, the precursor of the siderophore yersiniabactin. J Bacteriol 185, 5648-5653.

Rakin, A., Saken, E., Harmsen, D. \& Heesemann, J. (1994). The pesticin receptor of Yersinia enterocolitica: a novel virulence factor with dual function. Mol Microbiol 13, 253-263.

Rakin, A., Noelting, C., Schubert, S. \& Heesemann, J. (1999). Common and specific characteristics of the high-pathogenicity island of Yersinia enterocolitica. Infect Immun 67, 5265-5274.

Ratledge, C. \& Dover, L. G. (2000). Iron metabolism in pathogenic bacteria. Annu Rev Microbiol 54, 881-941.

Ruby, E. G., Urbanowski, M., Campbell, J. \& 13 other authors (2005). Complete genome sequence of Vibrio fischeri: a symbiotic bacterium with pathogenic congeners. Proc Natl Acad Sci U S A 102, 3004-3009.

Sambrook, J. \& Russell, D. W. (2001). Molecular Cloning: a Laboratory Manual. Cold Spring Harbor, NY: Cold Spring Harbor Laboratory.

Schubert, S., Rakin, A., Karch, H., Carniel, E. \& Heesemann, J. (1998). Prevalence of the "high pathogenicity island" of Yersinia species among Escherichia coli strains that are pathogenic to humans. Infect Immun 66, 480-485.
Schubert, S., Picard, B., Gouriou, S., Heesemann, J. \& Denamur, E. (2002). Yersinia high-pathogenicity island contributes to virulence in Escherichia coli causing extraintestinal infections. Infect Immun 70, 5335-5337.

Schwarzer, D., Finking, R. \& Marahiel, M. A. (2003). Nonribosomal peptides: from genes to products. Nat Prod Rep 20, 275-287.

Schwyn, B. \& Neilands, J. B. (1987). Universal chemical assay for the detection and determination of siderophores. Anal Biochem 160, 47-56.

Stachelhaus, T., Mootz, H. D. \& Marahiel, M. A. (1999). The specificity-conferring code of adenylation domains in nonribosomal peptide synthetases. Chem Biol 6, 493-505.

Stork, M., Di Lorenzo, M., Mouriño, S., Osorio, C. R., Lemos, M. L. \& Crosa, J. H. (2004). Two tonB systems function in iron transport in Vibrio anguillarum, but only one is essential for virulence. Infect Immun 72, 7326-7329.

Tanabe, T., Takata, N., Naka, A., Moon, Y. H., Nakao, H., Inoue, Y., Narimatsu, S. \& Yamamoto, S. (2005). Identification of an AraC-like regulator gene required for induction of the $78-\mathrm{kDa}$ ferrioxamine $\mathrm{B}$ receptor in Vibrio vulnificus. FEMS Microbiol Lett 249, 309-314.

Toranzo, A. E., Barja, J. L., Potter, S. A., Colwell, R. R., Hetrick, F. M. \& Crosa, J. H. (1983). Molecular factors associated with virulence of marine vibrios isolated from striped bass in Chesapeake Bay. Infect Immun 39, 1220-1227.

Vezzi, A., Campanaro, S., D’Angelo, M. \& 10 other authors (2005). Life at depth: Photobacterium profundum genome sequence and expression analysis. Science 307, 1459-1461.

Vokes, S. A., Reeves, S. A., Torres, A. G. \& Payne, S. M. (1999). The aerobactin iron transport system genes in Shigella flexneri are present within a pathogenicity island. Mol Microbiol 33, 63-73.

Wang, R. F. \& Kushner, S. R. (1991). Construction of versatile lowcopy-number vectors for cloning, sequencing, and gene expression in Escherichia coli. Gene 100, 195-199.

Williams, P. H. (1979). Novel iron uptake system specified by ColV plasmids: an important component in the virulence of invasive strains of Escherichia coli. Infect Immun 26, 925-932.

Winstanley, C. (2002). Spot the difference: applications of subtractive hybridisation to the study of bacterial pathogens. J Med Microbiol 51, 459-467.

Wyckoff, E. E., Stoebner, J. A., Reed, K. E. \& Payne, S. M. (1997). Cloning of a Vibrio cholerae vibriobactin gene cluster: identification of genes required for early steps in siderophore biosynthesis. J Bacteriol 179, 7055-7062. 